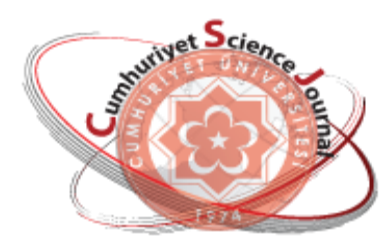

e-ISSN: $2587-246 X$

ISSN: $2587-2680$

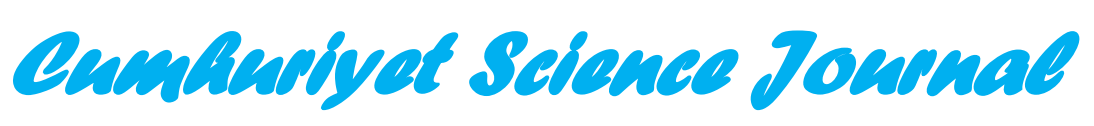

CSP

Cumhuriyet Sci. J., Vol.40-4 (2019) 819-829

\title{
Companions Of Perturbed Type Inequalities For Higher-Order Differentiable Functions
}

\author{
Samet ERDEN ${ }^{1}$ \\ ${ }^{1}$ Department of Mathematics, Faculty of Science, Bartin University, Bartın-TURKEY
}

Received: 13.06.2019; Accepted: 24.10.2019

http://dx.doi.org/10.17776/csj.577459

\begin{abstract}
First of all, a novel inequality of Hadamard's type for functions higher order derivatives of which are convex is developed. It is also presented midpoint type results. Afterward, Ostrowski type inequalities for mappings whose derivatives are either Lipschitzian or Hölder continuous with are established. Furthermore, links between results given in the earlier paper and our outcomes are examined.

Keywords: Convex Functions, Lipschitz Continuity, Ostrowski's Inequality, Hermite-Hadamard inequality.

\section{Yüksek Mertebeden Diferensiyellenebilir Fonksiyonlar için Perturbe Tipli Eşitsizliklerin Geliştirilmiş Durumları}

Özet. Bu çalışmada, ilk olarak yüksek mertebeden türevleri konveks olan fonksiyonlar için Hadamard tipli yeni bir eşitsizlik geliştirilmiş ve aynı zamanda bu eşitsizliğin orta nokta tarzındaki sonuçları sunulmuştur. Daha sonra, $n$. mertebeden türevleri ya Lipschitzyan ya da $\sigma \in(0,1]$ olmak üzere $\sigma-$ Hölder sürekli olan fonksiyonlar için Ostrowski tipli eşitsizlikler kurulmuştur. Bulunanlara ek olarak, bizim sonuçlarımız ile önceki makalelerde sunulmuş eşitsizlikler arasındaki bağlantılar incelenmiştir.
\end{abstract}

Anahtar Kelimeler: Konveks Fonksiyonlar, Lipschitzyan Süreklilik, Ostrowski Eşitsizliği, HermiteHadamard Eşitsizliği.

\section{INTRODUCTION}

The main purpose of the mathematical inequalities is to determine lower and upper bounds to mathematical expressions whose values are unknown exactly. So, inequality theory plays an important role in many areas of modern mathematics. Hermite-Hadamard inequality, introduced by C. Hermite and J. Hadamard but first published by Hadamard [1] in 1893, is one of the most significant inequalities in the literature because it gives an estimate of the mean value of a convex function. This inequality expresses that if $f: I \rightarrow \mathrm{R}$ is a convex function on the interval of real numbers and $a, b$ are elements of $I$ with $a<b$, then we have the chain of inequalities.

$$
f\left(\frac{a+b}{2}\right) \leq \frac{1}{b-a} \int_{a}^{b} f(x) d x \leq \frac{f(a)+f(b)}{2} .
$$

Another important inequality, published by Ostrowski [2] in 1938, is Ostrowski inequality obtained by using functions first derivatives of which are bound. This inequality is stated as follows: 
Let $f:[a, b] \rightarrow \mathrm{R}$ be a differentiable mapping on $(a, b)$ whose derivative $f^{\prime}:(a, b) \rightarrow \mathrm{R}$ is bounded on $(a, b)$, i.e. $\left\|f^{\prime}\right\|_{\infty}:=\sup _{t \in(a, b)}\left|f^{\prime}(t)\right|<\infty$. Then, we have the inequality

$$
\left|f(x)-\frac{1}{b-a} \int_{a}^{b} f(t) d t\right| \leq\left[\frac{1}{4}+\frac{\left(x-\frac{a+b}{2}\right)^{2}}{(b-a)^{2}}\right](b-a)\left\|f^{\prime}\right\|_{\infty},
$$

for all $x \in[a, b]$. The constant $\frac{1}{4}$ is the best possible.

These two inequalities have attracted many researchers due to its wide application areas. A large number of authors have devoted their effort to observed different generalizations, refined, counterparts and extensions of (1) and (2) for various classes of mappings. In particular, some generalizations of the inequalities (1) and (2) for differentiable, twice differentiable and higherorder differentiable mappings are studied. For instance, Sarikaya and Set derived some novel Ostrowski type results for twice differentiable functions by using a new Montgomery type identity in [3]. Moreover, results similar to Ostrowski's inequality are provided for functions second derivatives of which are bounded in [4] and [5]. On the other side, an extension of the inequality (1) for twice differentiable functions is presented by Farissi et al. in reference [6].

The interested mathematicians focused on perturbed type inequalities which give more general and more extensive outcomes of (1) and (2). In [7], the author developed an identity to establish some inequalities of perturbed Ostrowski type for absolutely continuous as follows.

Theorem 1. Let $f:[a, b] \rightarrow \mathrm{C}$ be an absolutely continuous on $[a, b]$ and $x \in[a, b]$. Then, for any $\lambda_{1}(x)$ and $\lambda_{2}(x)$ complex numbers, we have

$$
\begin{aligned}
& \frac{1}{b-a} \int_{a}^{x}(t-a)\left[f^{\prime}(t)-\lambda_{1}(x)\right] d t+\frac{1}{b-a} \int_{x}^{b}(t-b)\left[f^{\prime}(t)-\lambda_{2}(x)\right] d t \\
= & f(x)+\frac{1}{2(b-a)}\left[(b-x)^{2} \lambda_{2}(x)-(x-a)^{2} \lambda_{1}(x)\right]-\frac{1}{b-a} \int_{a}^{b} f(t) d t
\end{aligned}
$$

where the integrals in the left hand side are taken in the Lebesgue sense.

Afterward, researchers worked on perturbed inequalities for twice differentiable functions in [8] and [9].

We note that there are cases when first and second-order derivatives are not enough to solve certain mathematical issues. Hence, some researchers observed integral inequalities for higherorder differentiable mappings. As an illustration, authors provided some generalizations of Ostrowski type results for mappings higher-order derivatives are elements of $L_{1}, L_{p}$ or $L_{\infty}$ in [10], [11] and [12]. What is more, results that are higher order generalizations of HermiteHadamard inequality are deduced in [13] and [14]. In [15], Ozdemir and Yildiz examined midpoint formula related to (1) for higher order differentiable functions. In [16], Erden gave perturbed inequalities for mappings $n$.th derivatives of which are of bounded variation. In addition, it is presented some perturbed type integral inequalities for functions whose higherorder derivatives are either convex or Lipschitzian in [17]. 
In [18] and [19], Dragomir observed companions of Perturbed Ostrowski type inequalities for absolutely continuous functions. In [20], Erden established the following equality for $n$-times differentiable functions so as to refined Ostrowski type inequalities. He also investigated new quadrature rules to capture more effective results than the previous.

Lemma 1. Let $f:[a, b] \rightarrow \mathrm{R}$ be a $n$ - time differentiable function on $(a, b)$. Then, for any $\lambda_{i}(x), i=1,2,3$ complex numbers and all $x \in\left[a, \frac{a+b}{2}\right]$, we have the identity

$$
\begin{aligned}
& \int_{a}^{x} \frac{(t-a)^{n}}{n !}\left[f^{(n)}(t)-\lambda_{1}(x)\right] d t+\int_{x}^{a+b-x} \frac{1}{n !}\left(t-\frac{a+b}{2}\right)^{n}\left[f^{(n)}(t)-\lambda_{2}(x)\right] d t \\
& +\int_{a+b-x}^{b} \frac{(t-b)^{n}}{n !}\left[f^{(n)}(t)-\lambda_{3}(x)\right] d t \\
= & S(f: n, x)-\left[\lambda_{1}(x)+(-1)^{n} \lambda_{3}(x)\right] \frac{(x-a)^{n+1}}{(n+1) !} \\
& -\left[1+(-1)^{n}\right] \frac{\lambda_{2}(x)}{(n+1) !}\left(\frac{a+b}{2}-x\right)^{n+1}+(-1)^{n} \int_{a}^{b} f(t) d t,
\end{aligned}
$$

where $S(f: n, x)$ is defined by

$$
\begin{aligned}
& S(f: n, x) \\
& =\sum_{k=0}^{n-1} \frac{(-1)^{n+1}\left[f^{(k)}(a+b-x)+(-1)^{k} f^{(k)}(x)\right]}{(k+1) !}\left[(x-a)^{k+1}+(-1)^{k}\left(\frac{a+b}{2}-x\right)^{k+1}\right]
\end{aligned}
$$

In [21], Kashif et al. developed new results of Ostrowski type for functions $n$.th derivatives of which are element of either $L_{1}[a, b]$ or $L_{2}[a, b]$ by means of three-step kernel. Moreover, Qayyum et al. improved more comprehensive Ostrowski type results whose special cases give inequalities presented in the previous studies for functions having a five-step kernel in [22]. Both works also presented new efficient quadrature rules which can use to find the approximate value of expressions values of which cannot be calculated exactly.

In this study, our purpose is to establish new inequalities for mappings higher order derivatives of which are absolutely continuous. By utilizing the above equality, some companions of perturbed inequality for mappings higher order derivatives of which are either convex or Lipschitzian are examined. Results given in previous articles were recaptured when we gave specific values to the inequalities obtained in this work.

\section{INEQUALITIES FOR CONVEX FUNCTIONS}

Convex functions have become a cornerstone in many fields of Mathematics. Specifically, these type functions are a lot used in the inequality theory and optimization problems. The most famous of the inequalities obtained by using convex functions is Hermite-Hadamard inequality. Furthermore, midpoint and trapezoidal type results which are related to Hermite-Hadamard inequality plays an important role in a large number of areas of Mathematics. Now, we recall some definitions and properties concerning the convex functions which will use to establish our new results. 
Supposing that $I$ is an interval of real number with interior $I^{\circ}$. Also, $\varphi^{(n-1)}: I \rightarrow \mathrm{R}$ be a convex function on $I$. In this case, $\varphi^{(n-1)}$ is continuous on $I^{\circ}$ and possess finite left and right derivatives at each point of $I^{\circ}$. Furthermore, if $i$ and $j$ are element of $I^{\circ}$ and $i<j$, then $\varphi_{-}^{(n)}(i) \leq \varphi_{+}^{(n)}(i) \leq \varphi_{-}^{(n)}(j) \leq \varphi_{+}^{(n)}(j)$, and this situation shows that both $\varphi_{-}^{(n)}$ and $\varphi_{+}^{(n)}$ are non-decreasing functions on $I^{\circ}$. A convex function is well known to must be differentiable apart from at most countably many points.

We note that the sub differential of convex function $\varphi^{(n-1)}$ indicated by $\partial \varphi^{(n-1)}$ is the set of all functions $\omega: I \rightarrow[-\infty, \infty]$ such that $\omega\left(I^{\circ}\right) \subset \mathrm{R}$ satisfied the condition

$$
\varphi^{(n-1)}(i) \geq \varphi^{(n-1)}(m)+(i-m) \omega(m)
$$

for any $i, m \in I$. In this circumstance, if $\varphi^{(n-1)}$ is convex on $I$, then $\partial \varphi^{(n-1)}$ isn't empty, $\varphi_{-}^{(n)}$, $\varphi_{+}^{(n)} \in \partial \varphi^{(n-1)}$ and if $\omega$ is element of $\partial \varphi^{(n-1)}$, then

$$
\varphi_{-}^{(n)}(i) \geq \omega(i) \geq \varphi_{+}^{(n)}(i)
$$

for any $i \in I^{\circ}$. Specifically, $\omega$ is a nondecreasing mapping. Also, we must state that $\partial \varphi^{(n-1)}=\left\{\varphi^{(n)}\right\}$ if $f$ is differentiable and convex on $I^{\circ}$.

Theorem 2. Let $f:[a, b] \rightarrow \mathrm{R}$ be $n$ times differentiable function on $(a, b)$, and let $n$ be odd number. If $f^{(n-1)}$ is a convex function with the lateral derivatives $f_{+}^{(n)}(a)$ and $f_{-}^{(n)}(b)$, then one has the inequality

$$
\begin{aligned}
& \int_{a}^{b} f(t) d t \\
& \leq \sum_{k=0}^{n-1} \frac{\left[f^{(k)}(a+b-x)+(-1)^{k} f^{(k)}(x)\right]}{(k+1) !}\left[(x-a)^{k+1}+(-1)^{k}\left(\frac{a+b}{2}-x\right)^{k+1}\right] \\
& +\left[\frac{f_{-}^{(n)}(b)-f_{+}^{(n)}(a)}{(n+1) !}\right](x-a)^{n+1}
\end{aligned}
$$

for any $x \in\left[a, \frac{a+b}{2}\right]$.

Proof. If we take $\lambda_{1}(x)=f_{+}^{(n)}(a), \quad \lambda_{2}(x)=f_{+}^{(n)}\left(\frac{a+b}{2}\right), \lambda_{3}(x)=f_{-}^{(n)}(b)$ in the equality (3), since $n$ is odd number, then, for any $x \in\left[a, \frac{a+b}{2}\right]$, we possess the identity

$$
\begin{aligned}
& \sum_{k=0}^{n-1} \frac{\left[f^{(k)}(a+b-x)+(-1)^{k} f^{(k)}(x)\right]}{(k+1) !}\left[(x-a)^{k+1}+(-1)^{k}\left(\frac{a+b}{2}-x\right)^{k+1}\right] \\
& -\frac{f_{+}^{(n)}(a)-f_{-}^{(n)}(b)}{(n+1) !}(x-a)^{n+1}-\int_{a}^{b} f(t) d t
\end{aligned}
$$




$$
\begin{aligned}
= & \int_{a}^{x} \frac{(t-a)^{n}}{n !}\left[\omega(t)-f_{+}^{(n)}(a)\right] d t+\int_{a+b-x}^{b} \frac{(t-b)^{n}}{n !}\left[\omega(t)-f_{-}^{(n)}(b)\right] d t \\
& +\int_{x}^{a+b-x} \frac{1}{n !}\left(t-\frac{a+b}{2}\right)^{n}\left[\omega(t)-f_{+}^{(n)}\left(\frac{a+b}{2}\right)\right] d t
\end{aligned}
$$

where $\omega \in \partial f^{(n-1)}$, because $\omega$ is equal to $f^{(n)}$ almost everywhere on $[a, b]$.

Let $x$ be an element of $\left(a, \frac{a+b}{2}\right)$. One has

$$
(t-a)^{n}\left[\omega(t)-f_{+}^{(n)}(a)\right] \geq 0
$$

for any $t \in[a, x]$ and

$$
\left(t-\frac{a+b}{2}\right)^{n}\left[\omega(t)-f_{+}^{(n)}\left(\frac{a+b}{2}\right)\right] \geq 0
$$

for any $t \in[a, a+b-x]$. Also, as $n$ is odd number, we have

$$
(b-t)^{n}\left[f_{-}^{(n)}(b)-\omega(t)\right] \geq 0
$$

for any $t \in[a+b-x, b]$. Hence, the desired inequality is proved.

Corollary 1. Under the sane assumptions of Theorem 2 with $x=\frac{a+b}{2}$, then the following inequality hold:

$$
\begin{aligned}
& \int_{a}^{b} f(t) d t \leq \sum_{k=0}^{n-1} \frac{\left.\mid 1+(-1)^{k}\right\rfloor}{2^{k+1}(k+1) !} f^{(k)}\left(\frac{a+b}{2}\right)(b-a)^{k+1} \\
& +\left[\frac{f_{-}^{(n)}(b)-f_{+}^{(n)}(a)}{(n+1) !}\right]\left(\frac{b-a}{2}\right)^{n+1}
\end{aligned}
$$

which is a midpoint type inequality for mappings whose higher order derivatives are convex.

Corollary 2. Under all the all conditions of the Theorem 2, if we choose $x=\frac{3 a+b}{4}$, one has the result

$$
\begin{aligned}
& \int_{a}^{b} f(t) d t \\
& \leq \sum_{k=0}^{n-1} \frac{\left[f^{(k)}\left(\frac{a+3 b}{4}\right)+(-1)^{k} f^{(k)}\left(\frac{3 a+b}{4}\right)\right]}{4^{k+1}(k+1) !}\left[1+(-1)^{k}\right](b-a)^{k+1} \\
& +\left[\frac{f_{-}^{(n)}(b)-f_{+}^{(n)}(a)}{(n+1) !}\right]\left(\frac{b-a}{4}\right)^{n+1} .
\end{aligned}
$$

Remark 1. If we take $n=1$ in the inequality presented in the theorem 2 , we have 


$$
\begin{aligned}
& \frac{1}{b-a} \int_{a}^{b} f(t) d t \leq \frac{1}{2}[f(a+b-x)+f(x)] \\
& +\frac{1}{2}\left[\frac{f_{-}^{\prime}(b)-f_{+}^{\prime}(a)}{b-a}\right](x-a)^{2}
\end{aligned}
$$

which was proved by Dragomir in [19].

\section{SOME RESULTS FOR LIPSCHITZIAN DERIVATIVES}

Lipschitz continuity, which was called after Rudolf Lipschitz, is a more consistent form of uniform continuity. We began with the definition of Lipschitz continuity to this section.

$\phi:[a, b] \rightarrow \mathrm{R}$ is said to be Lipschitzian, if there exists a real constant $M>0$ such that

$$
|\phi(r)-\phi(s)| \leq M|r-s|
$$

for any $r, s \in[a, b]$.

A recent companion inequality for mappings whose higher order derivatives are Lipschitzian is provided in the following theorem.

Theorem 3. Let $f: I \rightarrow \mathrm{R}$ be a $n$ times differentiable function on $I^{\circ}$ and $[a, b] \subset I^{\circ}$. If the $n$th derivative $f^{(n)}: I^{\circ} \rightarrow \mathrm{R}$ is Lipschitzian with the constants $M_{1}, M_{2}$ and $M_{3}$ on $[a, x],[x, a+b-x]$ and $[a+b-x, b]$ respectively, then, for all $x$ in $\left[a, \frac{a+b}{2}\right]$, we have

$$
\begin{aligned}
& \mid S(f: n, x)-\left[f^{(n)}(x)+(-1)^{n} f^{(n)}(a+b-x)\right] \frac{(x-a)^{n+1}}{(n+1) !} \\
& -\frac{\left[1+(-1)^{n}\right]}{(n+1) !} f^{(n)}\left(\frac{a+b}{2}\right)\left(\frac{a+b}{2}-x\right)^{n+1}+(-1)^{n} \int_{a}^{b} f(t) d t \mid \\
& \leq\left[M_{1}+M_{3}\right] \frac{(x-a)^{n+2}}{(n+2) !}+M_{2} \frac{2}{n !(n+2)}\left(\frac{a+b}{2}-x\right)^{n+2}
\end{aligned}
$$

where $S(f: n, x)$ is defined as in (4).

Proof. Should we write $f^{(n)}(x), f^{(n)}\left(\frac{a+b}{2}\right)$ and $f^{(n)}(a+b-x)$ in place of $\lambda_{1}(x), \lambda_{2}(x)$ and $\lambda_{3}(x)$ in the equality (3) respectively, because of the triangle inequality, then we possess the outcome

$$
\begin{aligned}
& \mid S(f: n, x)-\left[f^{(n)}(x)+(-1)^{n} f^{(n)}(a+b-x)\right] \frac{(x-a)^{n+1}}{(n+1) !} \\
& -\frac{\left[1+(-1)^{n}\right]}{(n+1) !} f^{(n)}\left(\frac{a+b}{2}\right)\left(\frac{a+b}{2}-x\right)^{n+1}+(-1)^{n} \int_{a}^{b} f(t) d t \mid
\end{aligned}
$$




$$
\begin{aligned}
& \leq \int_{a}^{x} \frac{(t-a)^{n}}{n !}\left|f^{(n)}(t)-f^{(n)}(x)\right| d t+\int_{a+b-x}^{b} \frac{(b-t)^{n}}{n !}\left|f^{(n)}(t)-f^{(n)}(a+b-x)\right| d t \\
& \quad+\int_{x}^{a+b-x} \frac{1}{n !}\left|t-\frac{a+b}{2}\right|^{n}\left|f^{(n)}(t)-f^{(n)}\left(\frac{a+b}{2}\right)\right| d t .
\end{aligned}
$$

Seeing that $f^{(n)}: I^{\circ} \rightarrow \mathrm{C}$ is Lipschitzian with the constant $M_{1}$ on $[a, x]$, we get

$$
\begin{aligned}
& \int_{a}^{x} \frac{(t-a)^{n}}{n !}\left|f^{(n)}(t)-f^{(n)}(x)\right| d t \\
\leq & M_{1} \int_{a}^{x} \frac{(t-a)^{n}}{n !}(x-t) d t=M_{1} \frac{(x-a)^{n+2}}{(n+2) !} .
\end{aligned}
$$

Similarly, if the other two integrals in the right-hand side of (5) are observed, then the desired result can easily be obtained.

Corollary 3. Let $f: I \rightarrow \mathrm{R}$ be a $n$ times differentiable function on $I^{\circ}$ and $[a, b] \subset I^{\circ}$. Also, let $x \in(a, b)$. If the $n$th derivative $f^{(n)}: I^{\circ} \rightarrow \mathrm{R}$ is Lipschitzian with the constant $M$ on $[a, b]$, then one has

$$
\begin{aligned}
& \mid S(f: n, x)-\left[f^{(n)}(x)+(-1)^{n} f^{(n)}(a+b-x)\right] \frac{(x-a)^{n+1}}{(n+1) !} \\
& -\frac{\left[1+(-1)^{n}\right]}{(n+1) !} f^{(n)}\left(\frac{a+b}{2}\right)\left(\frac{a+b}{2}-x\right)^{n+1}+(-1)^{n} \int_{a}^{b} f(t) d t \mid \\
& \leq \frac{2 M}{(n+2) !}\left[(x-a)^{n+2}+(n+1)\left(\frac{a+b}{2}-x\right)^{n+2}\right]
\end{aligned}
$$

for any $x \in\left[a, \frac{a+b}{2}\right]$.

Remark 2. If we take $n=1$ in (6), the inequality (6) becomes

$$
\begin{aligned}
& \mid \frac{1}{2}[f(x)+f(a+b-x)] \\
& -\frac{1}{2}\left[f^{(n)}(x)-f^{(n)}(a+b-x)\right](x-a)^{2}-\int_{a}^{b} f(t) d t \mid \\
& \leq \frac{M}{3}\left[(x-a)^{3}+2\left(\frac{a+b}{2}-x\right)^{3}\right],
\end{aligned}
$$

which is provided by Dragomir in [19].

Furthermore, it can be derived trapezoidal and midpoint type inequalities by choosing $x=a$ and $x=\frac{a+b}{2}$ in the above results. 
Now, we deal with another result acquired by using a more comprehensive condition than Lipschitz continuity in the next theorem.

Theorem 4. Let $f: I \rightarrow \mathrm{R}$ be a $n$ time differentiable function on $I^{\circ}$ and $[a, b] \subset I^{\circ}$. If the conditions

$$
\begin{gathered}
\left|f^{(n)}(t)-f^{(n)}(a)\right| \leq L_{1}(t-a)^{\alpha} \quad \text { for any } t \in[a, x) \\
\left|f^{(n)}(t)-f^{(n)}\left(\frac{a+b}{2}\right)\right| \leq L_{2}\left|t-\frac{a+b}{2}\right|^{\beta} \quad \text { for any } t \in(x, a+b-x)
\end{gathered}
$$

and

$$
\left|f^{(n)}(t)-f^{(n)}(b)\right| \leq L_{3}(b-t)^{\gamma} \quad \text { for any } t \in[a, x)
$$

are satisfied for $\alpha, \beta, \gamma>-1$ and $L_{1}, L_{2}, L_{3}>0$, then, for any $x \in\left[a, \frac{a+b}{2}\right]$, we have the inequality

$$
\begin{aligned}
& \mid S(f: n, x)-\left[f^{(n)}(a)+(-1)^{n} f^{(n)}(b)\right] \frac{(x-a)^{n+1}}{(n+1) !} \\
& -\frac{\left[1+(-1)^{n}\right]}{(n+1) !} f^{(n)}\left(\frac{a+b}{2}\right)\left(\frac{a+b}{2}-x\right)^{n+1}+(-1)^{n} \int_{a}^{b} f(t) d t \mid \\
& \leq \frac{L_{1}}{n !} \frac{(x-a)^{n+\alpha+1}}{(n+\alpha+1)}+\frac{L_{3}}{n !} \frac{(x-a)^{n+\gamma+1}}{(n+\gamma+1)} \\
& +\frac{L_{2}}{n !} \frac{2}{(n+\beta+1)}\left(\frac{a+b}{2}-x\right)^{n+\beta+1}
\end{aligned}
$$

where $S(f: n, x)$ is as shown in (4).

Proof. We take absolute value of both sides of the equality (3) for $\lambda_{1}(x)=f^{(n)}(a)$, $\lambda_{2}(x)=f^{(n)}\left(\frac{a+b}{2}\right), \lambda_{3}(x)=f^{(n)}(b)$, due to the well-known triangle inequality, we get the inequality

$$
\begin{aligned}
& \mid S(f: n, x)-\left[f^{(n)}(a)+(-1)^{n} f^{(n)}(b)\right] \frac{(x-a)^{n+1}}{(n+1) !} \\
& -\frac{\left[1+(-1)^{n}\right]}{(n+1) !} f^{(n)}\left(\frac{a+b}{2}\right)\left(\frac{a+b}{2}-x\right)^{n+1}+(-1)^{n} \int_{a}^{b} f(t) \mid \\
& \quad \leq \int_{a}^{x} \frac{(t-a)^{n}}{n !}\left|f^{(n)}(t)-f^{(n)}(a)\right| d t+\int_{a+b-x}^{b} \frac{(b-t)^{n}}{n !}\left|f^{(n)}(t)-f^{(n)}(b)\right| d t \\
& \quad+\int_{x}^{a+b-x} \frac{1}{n !}\left|t-\frac{a+b}{2}\right|^{n}\left|f^{(n)}(t)-f^{(n)}\left(\frac{a+b}{2}\right)\right| d t .
\end{aligned}
$$

Now, should we calculate the first integral given in right hand side of the above inequality by 
utilizing the property (7), we possess

$$
\begin{aligned}
\int_{a}^{x} \frac{(t-a)^{n}}{n !}\left|f^{(n)}(t)-f^{(n)}(a)\right| d t & \leq L_{1} \int_{a}^{x} \frac{(t-a)^{n}}{n !}(t-a)^{\alpha} d t \\
& =L_{1} \frac{(x-a)^{n+\alpha+1}}{(n+\alpha+1) n !} .
\end{aligned}
$$

If we substitute the resulting inequalities in (11) after having estimated the other two integrals by using the properties (8) and (9), we can easily find the desired inequality (10) which finishes the proof.

In particular, if we take in consideration Hölder condition that is a generalization of the Lipschitzian, then we can express a new result as follows.

Corollary 4. Let $f: I \rightarrow \mathrm{R}$ be a $n$ time differentiable function on $I^{\circ}$ and $[a, b] \subset I^{\circ}$. If the $n$th derivative $f^{(n)}$ is $\sigma$-Hölder type on $[a, b]$, then we have the inequality

$$
\left|f^{(n)}(r)-f^{(n)}(s)\right| \leq K|r-s|^{\sigma}
$$

for any $r, s \in[a, b]$, where $r \in(0,1]$ and $H>0$. In this case, the following inequality holds:

$$
\begin{aligned}
& \mid S(f: n, x)-\left[f^{(n)}(a)+(-1)^{n} f^{(n)}(b)\right] \frac{(x-a)^{n+1}}{(n+1) !} \\
& -\frac{\left[1+(-1)^{n}\right]}{(n+1) !} f^{(n)}\left(\frac{a+b}{2}\right)\left(\frac{a+b}{2}-x\right)^{n+1}+(-1)^{n} \int_{a}^{b} f(t) d t \mid \\
& \leq \frac{2}{(n+\sigma+1)} \frac{K}{n !}\left[(x-a)^{n+\sigma+1}+\left(\frac{a+b}{2}-x\right)^{n+\sigma+1}\right]
\end{aligned}
$$

for any $x \in\left[a, \frac{a+b}{2}\right]$. Specifically, if we suppose that $f^{(n)}$ is Lipschitzian with the constant $K>0$ or if we take $\sigma=1$ in the above result, then, for any $x \in\left[a, \frac{a+b}{2}\right]$, we get

$$
\begin{aligned}
& \mid S(f: n, x)-\left[f^{(n)}(a)+(-1)^{n} f^{(n)}(b)\right] \frac{(x-a)^{n+1}}{(n+1) !} \\
& -\frac{\left[1+(-1)^{n}\right]}{(n+1) !} f^{(n)}\left(\frac{a+b}{2}\right)\left(\frac{a+b}{2}-x\right)^{n+1}+(-1)^{n} \int_{a}^{b} f(t) d t \mid \\
& \leq \frac{2}{(n+2)} \frac{L}{n !}\left[(x-a)^{n+2}+\left(\frac{a+b}{2}-x\right)^{n+2}\right],
\end{aligned}
$$

where $S(f: n, x)$ is as given in (4).

Remark 3. If we choose $n=1$ in (12), the inequality (12) reduce to the result 


$$
\begin{aligned}
& \left|[f(a+b-x)+f(x)] \frac{b-a}{2}-\left[f^{\prime}(a)-f^{\prime}(b)\right] \frac{(x-a)^{2}}{2}-\int_{a}^{b} f(t) d t\right| \\
\leq & \frac{2 K}{3}\left[(x-a)^{3}+\left(\frac{a+b}{2}-x\right)^{3}\right]
\end{aligned}
$$

that was presented by Dragomir in the reference [19].

In addition to all these result, the inequalities given in this section can be examined the cases when $x=\frac{a+b}{2}$ and $x=\frac{3 a+b}{4}$. What is more, it is clear that the cases when $n=1$ and $n=2$ of the results provided throughout this section relate to inequalities developed in some works listed in the references.

\section{REFERENCES}

[1] Hadamard J., Etude sur les proprietes des fonctions entieres et en particulier d'une fonction consideree par Riemann, J. Math. Pures Appl., 58 (1893), 171-215.

[2] Ostrowski A. M., Über die absolutabweichung einer differentiebaren funktion von ihrem integralmitelwert, Comment. Math. Helv. 10 (1938), 226-227.

[3] Sarikaya M. Z. and Set E., On new Ostrowski type Integral inequalities, Thai Journal of Mathematics, 12-1 (2014), 145-154.

[4] Dragomir S. S. and Barnett N. S., An Ostrowski type inequality for mappings whose second derivatives are bounded and applications, RGMIA Research Report Collection, 1-2 (1998).

[5] Dragomir S. S. and Sofo A., An integral inequality for twice differentiable mappings and application, Tamkang J. Math., 31-4 (2000).

[6] El Farissi A., Latreuch Z. and Belaidi B., Hadamard-Type inequalities for twice diffrentiable functions, RGMIA Reseaech Report collection, 12-1 (2009), art. 6.

[7] Dragomir S. S., Some perturbed Ostrowski type inequalities for absolutely continuous functions (I), Acta Universitatis Matthiae Belii, series Mathematics 23 (2015), 71-86.

[8] Budak H., Sarikaya M. Z. and Dragomir S. S., Some perturbed Ostrowski type inequality for twice differentiable functions, RGMIA Research Report Collection, 19, Article 47 (2016), 14 pp.

[9] Erden S., Budak H. and Sarikaya M. Z., Some perturbed inequalities of Ostrowski type for twice differentiable functions, RGMIA Research Report Collection, 19, Article 70 (2016), 11 pp.

[10] Cerone P., Dragomir S. S. and Roumeliotis J., Some Ostrowski type inequalities for n-time differentiable mappings and applications, Demonstratio Math., 32-4 (1999), 697-712.

[11] Sofo A., Integral inequalities for $\mathrm{n}$ - times differentiable mappings, with multiple branches, on the $L_{p}$ norm, Soochow Journal of Mathematics, 28-2 (2002), 179-221.

[12] Wang M. and Zhao X., Ostrowski type inequalities for higher-order derivatives, J. of 
Inequalities and App., Vol. 2009, Article ID 162689 (2009), 8 p.

[13] Latif M. A. and Dragomir S.S., On Hermite-Hadamard type integral inequalities for ntimes differentiable Log-Preinvex functions, Filomat, 29-7 (2015), 1651--1661.

[14] Latif M. A.,, and Dragomir S.S., Generalization of Hermite-Hadamard type inequalities for n-times differentiable functions which are s-preinvex in the second sense with applications, Hacettepe J. of Math. and Stat., 44-4 (2015), 389-853.

[15] Özdemir M. E. and Yıldız Ç., A new generalization of the midpoint formula for $n$-time differentiable mappings which are convex, arXiv:1404.5128v1, (2014).

[16] Erden S., Some perturbed inequalities of Ostrowski type for funtions whose $n$th derivatives are of bounded, Iranian Journal of Mathematical Sciences and Informatics, in press, (2019).

[17] Erden S., New perturbed inequalities for functions whose higher degree derivatives are absolutely continuous, Konuralp Journal of Mathematics, 7-2, (2019), 371-379.

[18] Dragomir S. S., Perturbed Companions of Ostrowski's Inequality for Absolutely Continuous Functions (I), Analele Universitatii de Vest, Timisoara Seria Matematica Informatica, LIV (1) (2016), 119- 138.

[19] Dragomir S. S., Perturbed Companions of Ostrowski's Inequality for Absolutely Continuous Functions (II), RGMIA Research Report Collection, 17, Article 19 (2014) 11 pp.

[20] Erden S., Refined Inequalities of Perturbed Ostrowski type for higher order absolutely continuous functions and applications, Submitted, (2019).

[21] Kashif A. R., Shoib M. and Latif M. A., Improved version of perturbed Ostrowski type inequalities for n-times di erentiable mappings with three-step kernel and its application, J. Nonlinear Sci. Appl. 9 (2016), 3319-3332.

[22] Qayyum A., Shoaib M. and Faye I., On new refinements and applications of efficient quadrature rules using $n$-times differentiable mappings, J. Computational Analysis abd Applicaions, 23-4 (2017), 723-739. 